\title{
A new coccidian parasite of the boodie, Bettongia lesueur (Mammalia: Marsupialia: Potoroidae), from Australia
}

\author{
Frances Hulst ${ }^{1}$, Leah F. Kemp ${ }^{2}$ and Jan Šlapeta ${ }^{3}$ \\ ${ }^{1}$ Taronga Zoo, Taronga Conservation Society Australia, Mosman, New South Wales, Australia; \\ ${ }^{2}$ Australian Wildlife Conservancy, Subiaco, Western Australia, Australia; \\ ${ }^{3}$ School of Life and Environmental Sciences, Faculty of Veterinary Science, The University of Sydney, New South Wales, Australia
}

\begin{abstract}
Four of 28 wild boodies or burrowing bettongs, Bettongia lesueur (Quoy et Gaimard) passed oocysts of species of Eimeria Schneider, 1875. The boodies are surviving on off-shore islands and in large predator-proof sanctuaries on the mainland where they were reintroduced. The boodie is a potoroid marsupial extinct from the mainland of Australia due to predation from red foxes and feral cats. Comparison with other species of the genus Eimeria indicates that the coccidium found represents a new species. Sporulated oocyst of Eimeria burdi sp. n. are pyriform, 21.0-24.0 $\mu \mathrm{m}$ (mean $22.6 \mu \mathrm{m}$ ) by 14.0-16.0 $\mu \mathrm{m}(14.9 \mu \mathrm{m})$, with a length/width ratio 1.31-1.71 (1.52) and 1- $\mu \mathrm{m}$-thick yellowish bilayered wall. Micropyle is present at the thinner apex end filled with hyaline body. Polar granules are absent. Sporocysts are ellipsoidal, $10.0-13.5 \mu \mathrm{m}(11.8 \mu \mathrm{m})$ by $7.0-8.5 \mu \mathrm{m}(7.4 \mu \mathrm{m})$, shape index is $1.42-1.89(1.63)$ and a very thin, poorly defined unilayered sporocyst wall is $0.2 \mu \mathrm{m}$ thick with a domelike almost indistinct Stieda body. Substieda body is indistinct.
\end{abstract}

Keywords: Coccidia, Apicomplexa, Eimeria, morphology, taxonomy, marsupials, bettongs, new species

Bettongs, potoroos and two of the rat-kangaroos belong to family Potoroidae Gray, a group of rabbit-sized marsupials endemic to Australia. The family includes four genera: Aepyprymnus Garrod, Bettongia Grey, Caloprymnus Thomas and Potorous Desmarest. Prior to European settlement there were 12 potoroids. In the past two centuries, four species have become extinct and two survive only on off-shore islands, despite previous distribution on the mainland (Woinarski et al. 2014).

The boodie or burrowing bettong, Bettongia lesueur (Quoy et Gaimard) (Mammalia: Marsupialia: Potoroidae) was once common in its former distribution across a wide span of the southern and central mainland of Australia. It is now extinct from the mainland due to predation from red foxes, Vulpes vulpes (Linnaeus), and feral cats, Felis catus Linnaeus, and survives only on a handful of small islands off the west coast of Australia and in large predator-proof sanctuaries on the mainland (Australian Wildlife Conservancy [AWC])'s Scotia and Yookamurra Sanctuaries; Arid Recovery) into which boodies have been reintroduced (Short and Turner 2000).

Parasitological studies on potoroids are scarce and for the boodie non-existent. Recent studies have focused on blood parasites, Trypanosoma spp., as a potential contributing factor in potoroids decline (Botero et al. 2013, Thompson et al. 2014). There are no coccidian parasites described from the boodie, despite four species of Eimeria Schneider, 1875 described from other potoroids (Barker et al. 1988, Duszynski 2016a). Here, we describe a new species of Eimeria from B. lesueur and compare it to those from potoroids.

\section{MATERIALS AND METHODS}

Faecal samples $(\mathrm{n}=28)$ from 28 individual Bettongia lesueur, the burrowing bettong or boodie, were collected in April, 2016 from animals living in AWC's Scotia Sanctuary, New South Wales 2648, Australia (3309'49"S; $141^{\circ} 07^{\prime} 38^{\prime \prime} \mathrm{E}$; Geodetic Coordinate System Australia 1994). This reintroduced population of B. lesueur lives wild in one of two 4000 ha predator-proof fenced areas within the sanctuary.

Samples were collected from either the trap or bag holding the animal or directly from the animal and a portion placed directly into a sodium-acetic acid formalin (SAF) solution and held at room temperature. Routine faecal flotation on fresh samples was performed to reveal presence of detectable parasitic stages. Faecal samples preserved in SAF were received at the Faculty of Veterinary Science, The University of Sydney. Sporulated oocysts were examined and photographed using Nomarski interference contrast microscopy. Thirty sporulated oocysts were measured using a calibrated ocular micrometre. Measurements in micrometres are reported as range followed by mean in parentheses. 


\section{RESULTS}

Eimeria burdi sp. n.

Figs. 1-7

ZooBank number for species:

urn:1sid:zoobank.org:act:CD9EB84E-6D53-4225-B374-60D66EFDA75D

Description (based on 30 sporulated oocysts): Sporulated oocysts pyriform, 21.0-24.0 (22.6) by 14.0-16.0 (14.9); shape index (length/width) 1.31-1.71 (1.52). Oocyst wall smooth, pale yellow. Oocyst wall bilayered, 1 thick (outer layer 0.8, inner layer 0.2). Oocyst residuum and polar granule absent. Thinner apex end with micropyle, approximately 4 across. Hyaline body filling apex of oocyst, mostly indistinct. Sporocysts ellipsoidal, 10.0-13.5 (11.8) by $7.0-8.5$ (7.4), with very thin, smooth, poorly defined unilayered sporocyst wall 0.2 thick. Sporocyst length/ width ratio $1.42-1.89$ (1.63). Stieda body almost indistinct, domelike, $\sim 1 \times 0.5$. Substieda body indistinct. Sporocyst residuum present, composed of numerous granules of approximately $0.2-0.5$ each, condensed into oval to irregular clusters of approximately 5 in diameter, filling space between sporozoites. Each sporocyst contains two sporozoites. Sporozoites broadly elongate, arranged head to tail within sporocyst. Sporozoites with two distinct refractile bodies, a larger (2-3) and a smaller (1-2). Sporozoite nucleus oval but indistinct, situated between refractile bodies. Sporozoites and sporozoite residuum float free within sporocyst. Sporozoite residuum not enclosed in membrane.

Type and only known host: Bettongia lesueur (Quoy et Gaimard) (Mammalia: Marsupialia: Potoroidae), burrowing bettong or boodie.

Type and only known locality: $33^{\circ} 09^{\prime} 49^{\prime \prime S}$; $141^{\circ} 07^{\prime} 38^{\prime \prime E}$; AWC' Scotia Sanctuary, via Wentworth, New South Wales 2648, Australia.

Distribution: Unknown.

Sporulation: Sporulated oocysts recovered from faeces transported from locality to the laboratory. The sample spent varying periods in transit (less than 10 hours) before reaching the laboratory where it was stored in SFA.

Prevalence : 14\% (found in four out of 28 examined faecal animals).

Prepatent and patent periods: Unknown.

$\mathrm{S}$ ite of infection: Unknown, oocysts recovered from faeces.

Endogenous stages: Unknown.

Type specimens: Phototypes are deposited at the Institute of Parasitology, Biology Centre of the Czech Academy of Sciences, Branišovská 31, České Buděovice, Czech Republic (No. IP Prot Coll 36).

E ty m o lo gy: The specific epithet burdi reflects the host local name 'burdi' of the Nyungar people of Western Australia and is given, in accordance with the International Code of Zoological Nomenclature (Article 31.1), as a noun in apposition (ICZN 1999).

Remarks. To these date, there are four species of coccidian parasites described from Potoroidae (Barker et al. 1988, Duszynski 2016a). Oocysts of our new species of Eimeria are different from those of all previously de-

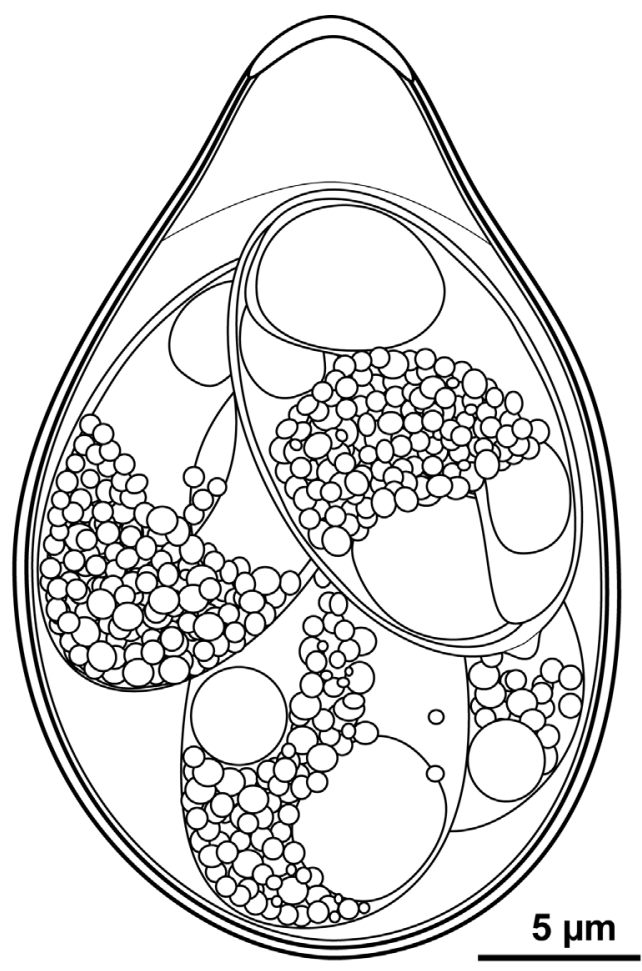

Fig. 1. Composite line drawing of sporulated oocyst of Eimeria burdi sp. n. from Bettongia lesueur (Quoy et Gaimard).

scribed species by size and shape, presence of a micropyle and absence of polar granule and oocyst residuum. The defined pyriform shape, smooth wall and size of oocysts, 21.0-24.0 $\mu \mathrm{m}(22.6 \mu \mathrm{m})$ by $14.0-16.0 \mu \mathrm{m}(14.9 \mu \mathrm{m})$, are the most distinct characters of Eimeria burdi sp. n. The closest oocyst of Eimeria potoroi Barker, O'Callaghan et Beveridge, 1988 from Potorus tridactylus (Kerr) (longnosed potoroo) is $26.2 \mu \mathrm{m} \times 18.5 \mu \mathrm{m}$ and was reported to be slightly pyriform and its wall radially striated with mamillated surface.

Oocysts of Eimeria gaimardi Barker, O'Callaghan et Beveridge, 1988 from Bettongia gaimardi (Desmarest) (Tasmanian bettong) are also slightly pyriform with mamillated surface. Oocysts of Eimeria aepyprymni Barker, O'Callaghan et Beveridge, 1988 from Aepyprymnus rufescens (Gray) (rufous bettong) and E. gaimardi are larger, $36.7 \mu \mathrm{m} \times 21.9 \mu \mathrm{m}$ and $34.6 \mu \mathrm{m} \times 24.3 \mu \mathrm{m}$, respectively, than those of Eimeria burdi. Eimeria mundayi Barker, O'Callaghan et Beveridge, 1988 from the long-nosed potoroo are smaller, spherical and possessing a polar granule (Barker et al. 1988, Duszynski 2016a).

\section{DISCUSSION}

Many coccidian parasites are host-specific (Barker et al. 1988, Duszynski 2016a) and the effect of these parasites on health and disease of potoroids is unknown. Reintroductions of declined animal populations should take into account the role of infectious agents such as parasites in the disease risk assessment (Jakob-Hoff et al. 2014). Parasites have to be considered when preserving host species from extinction, because with the host extinction, their microbiota, including their unique parasites, are also lost 

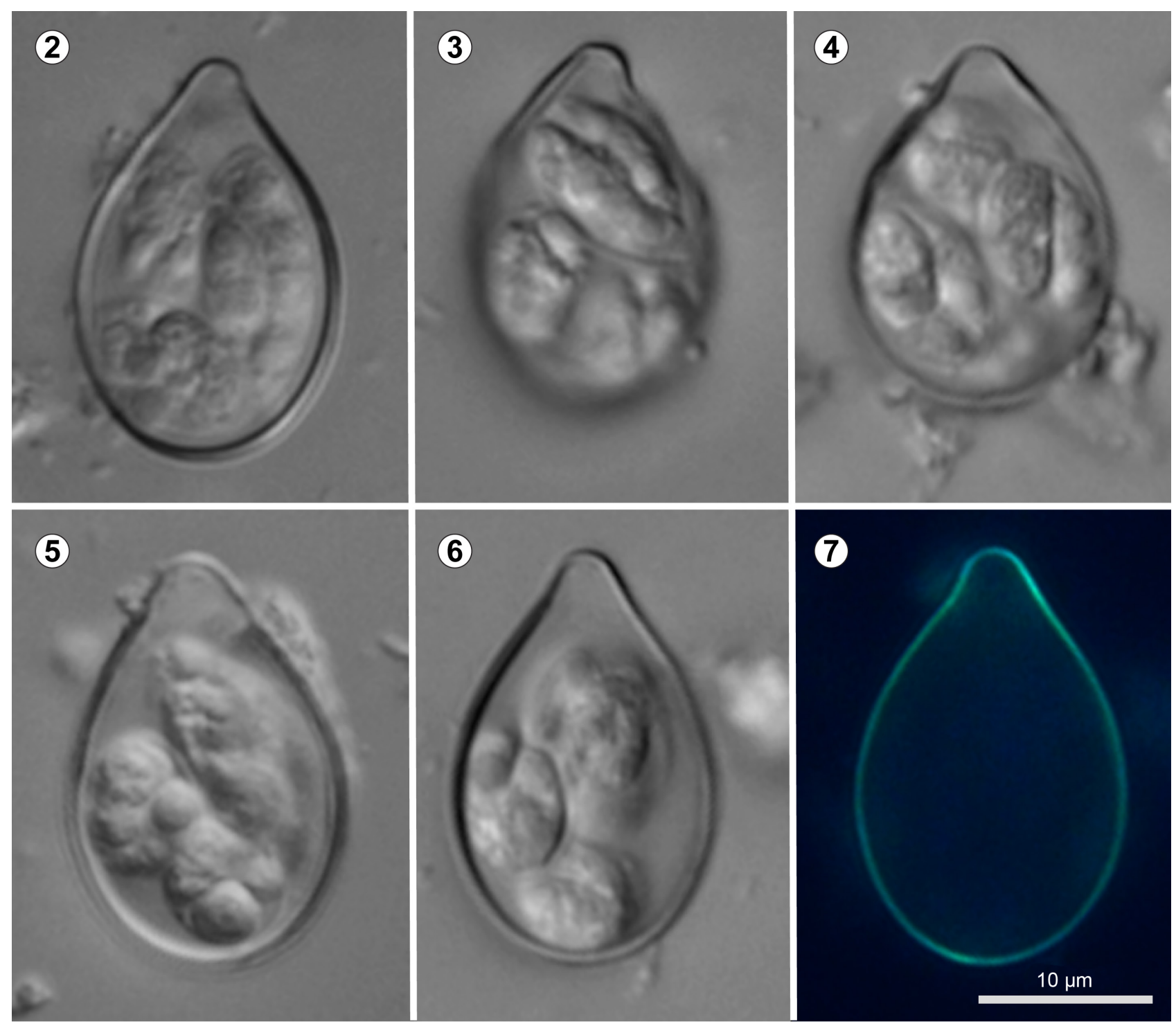

Figs. 2-7. The oocysts of Eimeria burdi sp. n. from Bettongia lesueur (Quoy et Gaimard). Figs. 2-6. Nomarski interference contrast photographs. Fig. 7. UV-fluorescence. Note the pyriform oocyst shape.

forever (Daszak et al. 2011). Coccidiosis (disease caused by species of Eimeria) can potentially be life-threatening in young captive marsupials (Vogelnest and Portas 2008).

Reports on coccidian parasites from potoroids are so far restricted to detection of oocysts in faeces from healthy wild or captive animals (Barker et al. 1988; the present study). For example, year-long presence of large numbers of Eimeria echidnae Barker, Beveridge et Munday, 1985 in long-term captive short-beaked echidnas, Tachyglossus aculeatus (Shaw), has not been associated with any health issues (Debenham et al. 2012). In fact, E. echidnae are considered normal microbiota of captive echidnas without the need for therapeutic management.

Seasonal occurrence of Eimeria burdi sp. n. across the very restricted distribution of the boodie is required to better understand the role the parasites play in health and disease. Similarly, it remains to be shown whether boodies from the Western Australian island whence the reintroduced animals were sourced are infected with $E$. burdi.

Recently, it has been argued that parasitologists have examined only $13 \%$ of all vertebrate species for coccidia (Duszynski 2016b). It is expected that a large majority of coccidia in Australia are unknown and yet to be described and their role in health and disease is yet to be understood.

Acknowledgements. This study was funded in part through the Faculty of Veterinary Science, University of Sydney diagnostic laboratory, the Australian Wildlife Conservancy and Taronga Zoo. We thank Sarah Panigas for assistance with sample collection, Katrina Gilchrist for laboratory support and the followers at https://www.facebook.com/UsydVetParasitology for interest in the selection of the new parasite name. 


\section{REFERENCES}

Barker I.K., O'Callaghan M.G., Beveridge I. 1988: Eimeria spp. (Apicomplexa: Eimeriidae) parasitic in the rat-kangaroos Hypsiprymnodon moschatus, Potorous tridactylus, Aepyprymnus rufescens and Bettongia gaimardi (Marsupialia: Potoroidae). Int. J. Parasitol. 18: 947-953.

Botero A., Thompson C.K., Peacock C.S., Clode P.L., Nicholls P.K., Wayne A.F., Lymbery A.J., Thompson R.C. 2013: Trypanosomes genetic diversity, polyparasitism and the population decline of the critically endangered Australian marsupial, the brush tailed bettong or woylie (Bettongia penicillata). Int. J. Parasitol. Parasites Wildl. 2: 77-89.

Daszak P., Ball S.J., Streicker D.G., Jones C.G., Snow K.R. 2011: A new species of Caryospora Léger, 1904 (Apicomplexa: Eimeriidae) from the endangered Round Island boa Casarea dussumieri (Schlegel) (Serpentes: Bolyeridae) of Round Island, Mauritius: an endangered parasite? Syst. Parasitol. 78: 117-122.

Debenham J.J., Johnson R., Vogelnest L., Phalen D.N., Whittington R., Šlapeta J. 2012: Year-long presence of Eimeria echidnae and absence of Eimeria tachyglossi in captive short-beaked echidnas (Tachyglossus aculeatus). J. Parasitol. 98: 543-549.

Duszynski D.W. 2016a: Chapter 4 - Order Diprotodontia Eimeriidae. In: D.W. Duszynski (Ed.), The Biology and Identification of the Coccidia (Apicomplexa) of Marsupials of the World. Academic Press, Boston, pp. 31-86.
DusZynski D.W. 2016b: Chapter 11 - Discussion, Summary, and Conclusions. In: D.W. Duszynski (Ed.), The Biology and Identification of the Coccidia (Apicomplexa) of Marsupials of the World. Academic Press, Boston, pp. 175-214.

ICZN 1999: International Code of Zoological Nomenclature. Fourth Edition, International Trust for Zoological Nomenclature, London, $306 \mathrm{pp}$.

Jakob-Hoff R.M., Macdiarmid S.C., Lees C., Miller P.S., Travis D., Kock R. 2014: Manual of Procedures for Wildlife Disease Risk Analysis. World Organisation for Animal Health. Published in association with the International Union for Conservation of Nature Species Survival Commission, Paris, 160 pp.

Short J., Turner B. 2000: Reintroduction of the burrowing bettong Bettongia lesueur (Marsupialia: Potoroidae) to mainland Australia. Biol. Cons. 96: 185-196.

Thompson C.K., Wayne A.F., Godfrey S.S., Thompson R.C. 2014: Temporal and spatial dynamics of trypanosomes infecting the brush-tailed bettong (Bettongia penicillata): a cautionary note of disease-induced population decline. Parasit. Vectors 7: 169.

Vogelnest L., Portas T. 2008: 7. Macropods. In: L. Vogelnest and R. Woods (Eds.), Medicine of Australian Mammals. CSIRO Publishing, Collingwood, pp. 133-225.

Woinarski J.C.Z., Burbidge A.A., Harrison P.L. 2014: The Action Plan for Australian Mammals 2012. CSIRO Publishing, Collingwood, $1056 \mathrm{pp}$. 